\title{
A new kinetic model for precipitation from solid solutions
}

\author{
O. Borysenko \\ National Science Center "Kharkiv Institute of Physics and Technology", 1 Akademichna St., \\ 61108 Kharkiv, Ukraine
}

Received September 16, 2014, in final form March 2, 2015

This model considers reversible elementary acts of migration of point defects (interstitials and/or vacancies) across the precipitate-matrix interface and enables one to derive equations for the rates of emission and absorption of solute atoms at the interface. The model predicts much stronger heterophase fluctuations and higher nucleation rates than the classical nucleation theory does. However, asymptotically, for large precipitate sizes and long ageing times, both models give the same results, being in agreement with the Lifshitz-SlyozovWagner theory of coarsening.

Key words: homogeneous nucleation, phase transformation kinetics, precipitation, point defects, precipitate-matrix interface

PACS: 64.60.Q- , 64.75.Nx, 68.35.Dv, 81.30.Mh

Quantitative studies of the kinetics of precipitation from solid solutions originate from the pioneering work by Ostwald [1]. The late stage of this process, called coarsening, is governed by the theory elaborated by Lifshitz, Slyozov [2] and Wagner [3] (LSW). At the same time, the general theory of precipitation is mainly based on the classical nucleation theory (CNT), including its modifications and extensions (see e.g., [4] and references therein), which is still debated in some of its aspects (see e.g., [5] and references therein). In particular, one of the open questions is a method of determination of the rates of emission and absorption in the master kinetic equation [5]. The present work is aimed at solving this problem.

This paper introduces a new phenomenological kinetic model for precipitation from solid solutions, being an extension of the recently published model of homogeneous semicoherent interphase boundary [6]. It considers the microscopic elementary acts of the reversible atomic rearrangements at the precipitate-matrix interface mediated by point defects (PDs). This approach enables one to determine the rates of emission and absorption in the master kinetic equation [see equations (29) and (30) below].

Consider an interphase boundary (Gibbs interface) between a precipitate consisting of one type of atoms and a solution of these atoms in a solid inert matrix. Let the interface between the precipitate and the matrix be coherent, i.e., most of the atomic planes be continuous across it. Since the bulk physical properties of such a heterophase structure are discontinuous across the interface, the number density (concentration) profiles of PDs are expected to be discontinuous as well. The PDs can penetrate across the interface via thermal activation or some other mechanism. Therefore, the transfer of PDs across the interface can be considered as a reversible surface chemical reaction.

A solute atom in the interstitial position located at one side of the interface can transfer to the other side of the interface and vice versa. This process can be represented in the form of a reversible chemical reaction:

$$
\mathrm{i}_{\mathrm{s}}^{\mathrm{p}} \rightleftharpoons \mathrm{i}_{\mathrm{s}}^{\mathrm{m}},
$$

where $\mathrm{i}_{\mathrm{s}}^{\varphi}$ denotes an interstitial solute atom in the precipitate $(\varphi=\mathrm{p})$ or in the matrix $(\varphi=\mathrm{m})$. In this case, the rate of transitions, represented by equation (1), in each direction, is proportional to the concentration $c_{\mathrm{i}_{\mathrm{s}}}^{\varphi}$ of the interstitials $\mathrm{i}_{\mathrm{s}}^{\varphi}$ in the corresponding phase. The normal component of the flux of solute atoms 
across the interface via the interstitial mechanism is as follows (hereinafter the normal unit vector is supposed to be directed from the precipitate into the matrix):

$$
j_{\mathrm{i}_{\mathrm{s}}}=\beta_{\mathrm{i}_{\mathrm{s}}}^{\mathrm{p}} c_{\mathrm{i}_{\mathrm{s}}}^{\mathrm{p}}-\beta_{\mathrm{i}_{\mathrm{s}}}^{\mathrm{m}} c_{\mathrm{i}_{\mathrm{s}}}^{\mathrm{m}}
$$

$\beta_{\mathrm{i}_{\mathrm{s}}}^{\varphi}$ being a phenomenological transition kinetic coefficient for the solute interstitials in the corresponding phase.

A solute atom located at a regular lattice site at one side of the interface can transfer to the neighbouring vacant site at the other side of the interface and vice versa. This process can be represented in the form of a reversible chemical reaction:

$$
\mathrm{l}_{\mathrm{s}}^{\mathrm{p}}+\mathrm{v}^{\mathrm{m}} \rightleftharpoons \mathrm{l}_{\mathrm{s}}^{\mathrm{m}}+\mathrm{v}^{\mathrm{p}}
$$

where $\mathrm{l}_{\mathrm{s}}^{\mathrm{p}}$ is a solute atom at a regular lattice site of the precipitate; $\mathrm{v}^{\mathrm{m}}$ is a vacant regular lattice site in the matrix; $\mathrm{l}_{\mathrm{s}}^{\mathrm{m}}$ is a solute atom at a regular lattice site of the matrix; $\mathrm{v}^{\mathrm{p}}$ is a vacant regular lattice site in the precipitate. Therefore, the rate of transitions, represented by equation (3), in each direction, should be bilinear in concentrations of the corresponding reagents. The normal component of the flux of solute atoms across the interface via the vacancy mechanism is as follows:

$$
j_{\mathrm{v}_{\mathrm{s}}}=\beta_{\mathrm{v}_{\mathrm{s}}}^{\mathrm{m}} c_{\mathrm{l}_{\mathrm{s}}}^{\mathrm{p}} c_{\mathrm{v}}^{\mathrm{m}}-\beta_{\mathrm{v}_{\mathrm{s}}}^{\mathrm{p}} c_{\mathrm{l}_{\mathrm{s}}}^{\mathrm{m}} c_{\mathrm{v}}^{\mathrm{p}}
$$

Here, $c_{\mathrm{l}_{\mathrm{s}}}^{\mathrm{p}}$ is the concentration of solute atoms that belong to the regular lattice sites of the precipitate, $c_{\mathrm{v}}^{\mathrm{m}}$ is the concentration of vacancies in the matrix, $c_{\mathrm{l}_{\mathrm{s}}}^{\mathrm{m}}$ is the concentration of solute atoms at the regular lattice sites of the matrix, $c_{\mathrm{v}}^{\mathrm{p}}$ is the concentration of vacancies in the precipitate and $\beta_{\mathrm{v}_{\mathrm{s}}}^{\varphi}$ is a phenomenological transition kinetic coefficient for vacancies in the corresponding phase.

An interstitial atom located at one side of the interface can recombine with a vacancy located at the other side:

$$
\mathrm{i}_{\mathrm{s}}^{\mathrm{p}}+\mathrm{v}^{\mathrm{m}} \rightarrow \mathrm{l}_{\mathrm{s}}^{\mathrm{m}} ; \quad \mathrm{i}_{\mathrm{s}}^{\mathrm{m}}+\mathrm{v}^{\mathrm{p}} \rightarrow \mathrm{l}_{\mathrm{s}}^{\mathrm{p}}
$$

These are irreversible reactions because an energy threshold for production of the Frenkel pairs is usually large. The normal component of the flux of solute atoms via the recombination mechanism (5) is as follows:

$$
j_{\mathrm{R}_{\mathrm{s}}}=\alpha_{\mathrm{R}_{\mathrm{s}}}^{\mathrm{p}} c_{\mathrm{i}_{\mathrm{s}}}^{\mathrm{p}} c_{\mathrm{v}}^{\mathrm{m}}-\alpha_{\mathrm{R}_{\mathrm{s}}}^{\mathrm{m}} c_{\mathrm{i}_{\mathrm{s}}}^{\mathrm{m}} c_{\mathrm{v}}^{\mathrm{p}}
$$

where $\alpha_{\mathrm{R}_{\mathrm{s}}}^{\varphi}$ is a phenomenological recombination kinetic coefficient in the corresponding phase.

The total flux of solute atoms across the interface is a sum of the contributions given by equations (2), (4) and (6):

$$
j_{\mathrm{s}}=j_{\mathrm{i}_{\mathrm{s}}}+j_{\mathrm{v}_{\mathrm{s}}}+j_{\mathrm{R}_{\mathrm{s}}} .
$$

A total concentration of solute atoms in the corresponding phase consists of the concentrations of the atoms in both the interstitial and regular positions: $c_{\mathrm{s}}^{\varphi}=c_{\mathrm{i}_{\mathrm{s}}}^{\varphi}+c_{\mathrm{l}_{\mathrm{s}}}^{\varphi}$. One can consider the following relations between the concentrations of solute atoms in different lattice positions:

$$
c_{\mathrm{i}_{\mathrm{s}}}^{\varphi}=x_{\mathrm{s}}^{\varphi} c_{\mathrm{s}}^{\varphi} ; \quad c_{\mathrm{l}_{\mathrm{s}}}^{\varphi}=\left(1-x_{\mathrm{s}}^{\varphi}\right) c_{\mathrm{s}}^{\varphi}
$$

where $x_{\mathrm{s}}^{\varphi}$ is a dimensionless constant taking its value from the range $0 \leqslant x_{\mathrm{s}}^{\varphi} \leqslant 1$. The lower and upper limiting values correspond to the cases when the solute atoms reside only in the regular and interstitial lattice positions, respectively. Then, taking into account equations (2), 44, (6) and (8), one can represent equation (7) as follows:

$$
j_{\mathrm{s}}=c_{\mathrm{s}}^{\mathrm{p}}\left[\beta_{\mathrm{i}_{\mathrm{s}}}^{\mathrm{p}} x_{\mathrm{s}}^{\mathrm{p}}+\beta_{\mathrm{v}_{\mathrm{s}}}^{\mathrm{m}} c_{\mathrm{v}}^{\mathrm{m}}\left(1-x_{\mathrm{s}}^{\mathrm{p}}\right)+\alpha_{\mathrm{R}_{\mathrm{s}}}^{\mathrm{p}} x_{\mathrm{s}}^{\mathrm{p}} c_{\mathrm{v}}^{\mathrm{m}}\right]-c_{\mathrm{s}}^{\mathrm{m}}\left[\beta_{\mathrm{i}_{\mathrm{s}}}^{\mathrm{m}} x_{\mathrm{s}}^{\mathrm{m}}+\beta_{\mathrm{v}_{\mathrm{s}}}^{\mathrm{p}} c_{\mathrm{v}}^{\mathrm{p}}\left(1-x_{\mathrm{s}}^{\mathrm{m}}\right)+\alpha_{\mathrm{R}_{\mathrm{s}}}^{\mathrm{m}} x_{\mathrm{s}}^{\mathrm{m}} c_{\mathrm{v}}^{\mathrm{p}}\right]
$$


The state of kinetic equilibrium at the interface is determined by the condition of solute balance between the precipitate and the matrix:

$$
j_{\mathrm{s}}^{\mathrm{eq}}=0 .
$$

Taking into account equation (9), one can find from equation (10) the relation between the equilibrium solute and PDs concentrations at the interface:

$$
\frac{c_{\mathrm{s}}^{\mathrm{m} \text { eq }}}{c_{\mathrm{s}}^{\mathrm{p} \text { eq }}}=\frac{\beta_{\mathrm{i}_{\mathrm{s}}}^{\mathrm{p}} x_{\mathrm{s}}^{\mathrm{p} \text { eq }}+\left[\beta_{\mathrm{v}_{\mathrm{s}}^{\mathrm{m}}}^{\mathrm{m}}\left(1-x_{\mathrm{s}}^{\mathrm{p} \mathrm{eq}}\right)+\alpha_{\mathrm{R}_{\mathrm{s}}^{\mathrm{p}}}^{\mathrm{p}} x_{\mathrm{s}}^{\mathrm{p} \mathrm{eq}}\right] c_{\mathrm{v}}^{\mathrm{m} \text { eq }}}{\beta_{\mathrm{i}_{\mathrm{s}}}^{\mathrm{m}} x_{\mathrm{s}}^{\mathrm{m} \text { eq }}+\left[\beta_{\mathrm{v}_{\mathrm{s}}}^{\mathrm{p}}\left(1-x_{\mathrm{s}}^{\mathrm{m} \text { eq }}\right)+\alpha_{\mathrm{R}_{\mathrm{s}}}^{\mathrm{m}} x_{\mathrm{s}}^{\mathrm{m} \text { eq }}\right] c_{\mathrm{v}}^{\mathrm{p} \mathrm{eq}}} .
$$

Provided that the thermal equilibrium between the precipitate and the matrix holds (which is usually true for solids that exhibit high thermal conductivity), the conditions of kinetic and thermodynamic equilibrium should be equivalent. Therefore, equation (11) is equivalent to the Gibbs-Thomson relation for the equilibrium solute concentration near the interface:

$$
c_{\mathrm{s}}^{\mathrm{m} \text { eq }}\left(r_{\mathrm{p}}\right)=c_{\mathrm{s}}^{\mathrm{m} \text { eq }} \exp \left(a / r_{\mathrm{p}}\right) \text {, }
$$

where $c_{\mathrm{s}}^{\mathrm{m}}$ eq is a thermodynamic equilibrium solubility, $r_{\mathrm{p}}$ is the radius of the precipitate and

$$
a=2 \gamma \omega_{0} / k_{\mathrm{B}} T
$$

is the Gibbs-Thomson parameter with a dimension of length. Here, $\gamma$ is the coefficient of the surface tension at the interface, $\omega_{0}$ is the mean atomic volume, $k_{\mathrm{B}}$ is the Boltzmann's constant and $T$ is temperature.

Now, we consider the problem of solute diffusion in the matrix near the spherical precipitate of radius $r_{\mathrm{p}}$. A steady-state solute concentration profile in the matrix is subjected to the following diffusion equation:

$$
\operatorname{div} j_{\mathrm{s}}^{\mathrm{m}}=0 ; \quad j_{\mathrm{s}}^{\mathrm{m}}=-D_{\mathrm{s}}^{\mathrm{m}} \nabla c_{\mathrm{s}}^{\mathrm{m}},
$$

where $D_{\mathrm{s}}^{\mathrm{m}}$ is the solute diffusion coefficient in the matrix.

The normal component of the solute flux across the interface is given by equation (9). In the first order in a deviation of the solute concentration at the interface from its kinetic equilibrium value (11), equation (9) becomes

$$
j_{\mathrm{s}}^{\mathrm{m}}\left(r_{\mathrm{p}}\right)=D_{\mathrm{s}}^{\mathrm{m}}\left[c_{\mathrm{s}}^{\mathrm{m}}{ }^{\mathrm{eq}}\left(r_{\mathrm{p}}\right)-c_{\mathrm{s}}^{\mathrm{m}}\left(r_{\mathrm{p}}\right)\right] / l,
$$

where

$$
l=D_{\mathrm{s}}^{\mathrm{m}} /\left\{\beta_{\mathrm{i}_{\mathrm{s}}}^{\mathrm{m}} x_{\mathrm{s}}^{\mathrm{m} \text { eq }}+\left[\beta_{\mathrm{v}_{\mathrm{s}}}^{\mathrm{p}}\left(1-x_{\mathrm{s}}^{\mathrm{m} \mathrm{eq}}\right)+\alpha_{\mathrm{R}_{\mathrm{s}}}^{\mathrm{m}} x_{\mathrm{s}}^{\mathrm{m} \text { eq }}\right] c_{\mathrm{v}}^{\mathrm{p} \text { eq }}\right\}
$$

is the model parameter with a dimension of length. One can notice a similarity between equation (15) and the Ohm's law. By this analogy, the parameter $D_{\mathrm{s}}^{\mathrm{m}} / l$ can be considered as a "conductivity" of the interface, which comprises the interstitial, vacancy and recombination mechanisms of mobility of solute atoms.

One can consider the second boundary condition as follows:

$$
c_{\mathrm{s}}^{\mathrm{m}}(\infty)=\bar{c}_{\mathrm{s}}^{\mathrm{m}},
$$

where $\bar{c}_{\mathrm{s}}^{\mathrm{m}}$ is an average concentration of single solute atoms (momomers) in the matrix.

The solution of the diffusion equation (14) with the boundary conditions, given by equations (15) and (17), gives:

$$
c_{\mathrm{s}}^{\mathrm{m}}\left(r_{\mathrm{p}}\right)=\bar{c}_{\mathrm{s}}^{\mathrm{m}}+r_{\mathrm{p}}\left[c_{\mathrm{s}}^{\mathrm{m} \text { eq }}\left(r_{\mathrm{p}}\right)-\bar{c}_{\mathrm{s}}^{\mathrm{m}}\right] /\left(r_{\mathrm{p}}+l\right) .
$$

A total number $N=4 \pi r_{\mathrm{p}}^{3} / 3 \omega_{0}$ of atoms entering the precipitate is subject to the following kinetic equation:

$$
\mathrm{d} N / \mathrm{d} t=-4 \pi r_{\mathrm{p}}^{2} j_{\mathrm{s}}\left(r_{\mathrm{p}}\right)=-4 \pi r_{\mathrm{p}}^{2} D_{\mathrm{s}}^{\mathrm{m}}\left[c_{\mathrm{s}}^{\mathrm{m}} \mathrm{eq}\left(r_{\mathrm{p}}\right)-c_{\mathrm{s}}^{\mathrm{m}}\left(r_{\mathrm{p}}\right)\right] / l
$$


This equation can be reformulated in terms of the rates of emission and absorption of solute atoms [i.e., the rates of direct and inverse reactions (1), (3) and (5)] at the interface in the following way:

$$
\mathrm{d} N / \mathrm{d} t=w_{\mathrm{a}}-w_{\mathrm{e}}
$$

where

$$
\begin{aligned}
& w_{\mathrm{e}}=4 \pi r_{\mathrm{p}}^{2} D_{\mathrm{s}}^{\mathrm{m}} c_{\mathrm{s}}^{\mathrm{m} \text { eq }}\left(r_{\mathrm{p}}\right) / l \text {; } \\
& w_{\mathrm{a}}=4 \pi r_{\mathrm{p}}^{2} D_{\mathrm{s}}^{\mathrm{m}} c_{\mathrm{s}}^{\mathrm{m}}\left(r_{\mathrm{p}}\right) / l
\end{aligned}
$$

are respectively the rates of emission and absorption of solute atoms obtained by decomposition of the right-hand side of equation (19) into the negative and positive parts.

Herein below, we study the case of homogeneous precipitation from a solid solution within the framework of the Becker-Döring approach [7]. In further considerations it is convenient to change to a dimensionless time variable

$$
\tau=t \cdot 4 \pi r_{0} D_{\mathrm{s}}^{\mathrm{m}} c_{\mathrm{s}}^{\mathrm{m}} \text { eq }
$$

where $r_{0}=\sqrt[3]{3 \omega_{0} / 4 \pi}$.

A distribution function $g(N, \tau)$ of precipitates in the dimension space is subject to the next kinetic (master) equation [7], valid for $N>1$ :

$$
\begin{gathered}
\operatorname{dg}(N, \tau) / \mathrm{d} \tau=J_{N-1, N}-J_{N, N+1} ; \\
J_{N-1, N}=w_{\mathrm{a}}(N-1) g(N-1, \tau)-w_{\mathrm{e}}(N) g(N, \tau) .
\end{gathered}
$$

As a boundary condition, the following expression is used:

$$
g\left(N_{\max }, \tau\right)=0 .
$$

Here, $N_{\max }$ stands for the number of atoms in the biggest precipitate under consideration. It is assumed that for all $N \geqslant N_{\max }$ the distribution function is zero. According to Lifshitz and Slyozov [2], at the late stage of the precipitation process, the value of $N_{\max }$ grows linearly with time. The results presented herein below in figures 2 and 3 are obtained with $N_{\max }=10^{12}$.

The system of equations (24) must be supplemented with an additional equation for the value

$$
g(1, \tau)=\bar{c}_{\mathrm{s}}^{\mathrm{m}}(\tau) / c_{\mathrm{s}}^{\mathrm{m}}{ }^{\mathrm{eq}}
$$

in order to satisfy the law of conservation of the total amount of solute atoms $q$ [see equation (35) below]:

$$
\mathrm{d} g(1, \tau) / \mathrm{d} \tau=-\sum_{N=2}^{N_{\max }} N \mathrm{~d} g(N, \tau) / \mathrm{d} \tau .
$$

From equations (21), 22), taking into account equations (12), 18) and time renormalization (23), one finds:

$$
\begin{gathered}
w_{\mathrm{e}}(N)=\frac{\sqrt[3]{N^{2}}}{\lambda} \exp \left(\frac{\alpha}{\sqrt[3]{N}}\right) ; \\
w_{\mathrm{a}}(N)=\frac{\sqrt[3]{N^{2}}}{\lambda} \exp \left(\frac{\alpha}{\sqrt[3]{N}}\right)\left\{1+\left[g(1, \tau) \exp \left(-\frac{\alpha}{\sqrt[3]{N}}\right)-1\right] \frac{\lambda}{\lambda+\sqrt[3]{N}}\right\},
\end{gathered}
$$

where $\alpha=a / r_{0}$ and $\lambda=l / r_{0}$. 
Equations (29) and (30) for the rates of emission and absorption at the interface are the key result of the present model. They need to be compared to the corresponding equations derived in the CNT (see e.g., [4] and references therein), when the interface kinetics is taken into account. In the present notations, the CNT expressions for the rates of emission and absorption are as follows:

$$
\begin{gathered}
w_{\mathrm{e}}^{\mathrm{CNT}}(N)=\frac{\sqrt[3]{N^{2}}}{\lambda+\sqrt[3]{N}} \exp \left(\frac{\alpha}{\sqrt[3]{N}}\right) ; \\
w_{\mathrm{a}}^{\mathrm{CNT}}(N)=\frac{\sqrt[3]{N^{2}}}{\lambda+\sqrt[3]{N}} g(1, \tau) .
\end{gathered}
$$

From equation (32) one can see that $w_{\mathrm{a}}^{\mathrm{CNT}}=0$ for $\bar{c}_{\mathrm{s}}^{\mathrm{m}}=0$, while, according to equation (18), the steadystate concentration of solute atoms at the interface remains finite in this case: $c_{\mathrm{s}}^{\mathrm{m}}\left(r_{\mathrm{p}}\right)=$ $c_{\mathrm{s}}^{\mathrm{m}}{ }^{\text {eq }}\left(r_{\mathrm{p}}\right) r_{\mathrm{p}} /\left(r_{\mathrm{p}}+l\right)$. It means that, once the solute atom has crossed the interface (via one elementary jump), within the framework of CNT it has no chance to jump back. On the contrary, the present theory considers reversible elementary acts at the interface [see equations (1) and (3)]. On the other hand, from general speculations it follows that the rate of emission ("evaporation") should be proportional to the area of the interface, i.e., $w_{\mathrm{e}} \propto \sqrt[3]{N^{2}}$. In the present model, this condition is satisfied for any $N$ [see equation [29)], while in CNT it is satisfied only for $\sqrt[3]{N} \ll \lambda$ [see equation (31)].Therefore, by neglecting reversible elementary acts at the interface, CNT underestimates the rates of emission and absorption of solute atoms. At the same time, the value $\mathrm{d} N / \mathrm{d} \tau=w_{\mathrm{a}}-w_{\mathrm{e}}$, which is determined by the diffusioncontrolled net solute flux in the matrix, is equal both in CNT and in this model. That is why both models give the same result in the asymptotic coarsening regime, but differ in the range of ultrafine precipitates (see figure 2 below). It should be noted that the results of this model are asymptotically equivalent to those of the CNT for $\lambda \gg \sqrt[3]{N}$ [cf. equations (29), (31) and (30), (32)]. Great values of the parameter $\lambda$ correspond to the interface-limited precipitation regime, when the "conductivity" of the interface is small compared to the bulk one.

Under the condition of a detailed balance, when the flux of precipitates in the dimension space 25 turns to zero for any $N$ :

$$
J_{N-1, N}=0, \quad \forall N
$$

a stationary distribution function $g_{0}(N)$ is given by the expression:

$$
g_{0}(N)=\left\{\begin{array}{l}
g_{0}(1), \quad N=1 ; \\
g_{0}(1) \prod_{i=2}^{N} w_{\mathrm{a}}(i-1) / w_{\mathrm{e}}(i), \quad N>1 .
\end{array}\right.
$$

Provided that $\lim _{N \rightarrow \infty} g_{0}(N)=0$, the condition (33) may be satisfied in the range $0 \leqslant g_{0}(1) \leqslant 1$, which corresponds to the case of undersaturated and saturated solute concentrations [see equation (27)].

A total concentration of solute atoms in the matrix (expressed in the units of $c_{\mathrm{s}}^{\mathrm{m}}$ eq ) can be calculated as follows:

$$
q=\sum_{N=1}^{N_{\max }} N g(N) .
$$

In the limiting case $g_{0}^{*}(1)=1$, corresponding to the saturated solute concentration, equation (35) with $g(N)=g_{0}^{*}(N)$ can be utilized to calculate the total solubility limit, taking into account both the solute monomers and heterophase fluctuations (subcritical precipitates).

Figure 1 shows the total solubility limit

$$
q^{*}=\sum_{N=1}^{N_{\max }} N g_{0}^{*}(N)
$$

as a function of two dimensionless model parameters $\alpha$ and $\lambda$ entering equations (29) and (30). From figure 1 one can see that, within the present model, a contribution from heterophase fluctuations to 


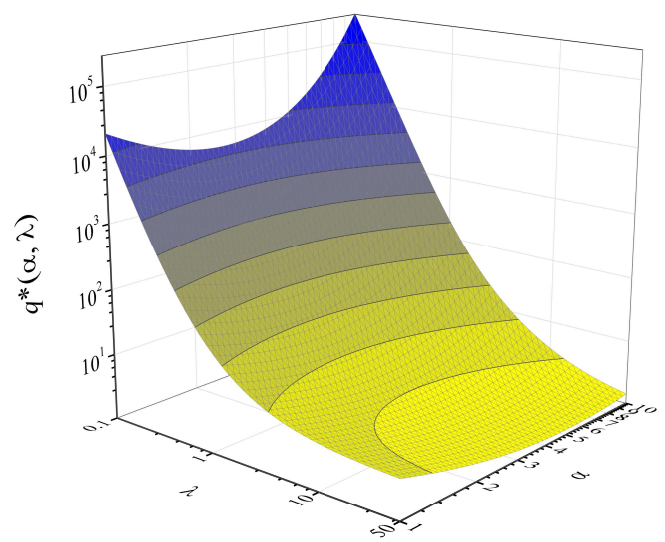

Figure 1. (Color online) A total solubility limit $q^{*}$ (36) vs model parameters $\alpha$ and $\lambda$.

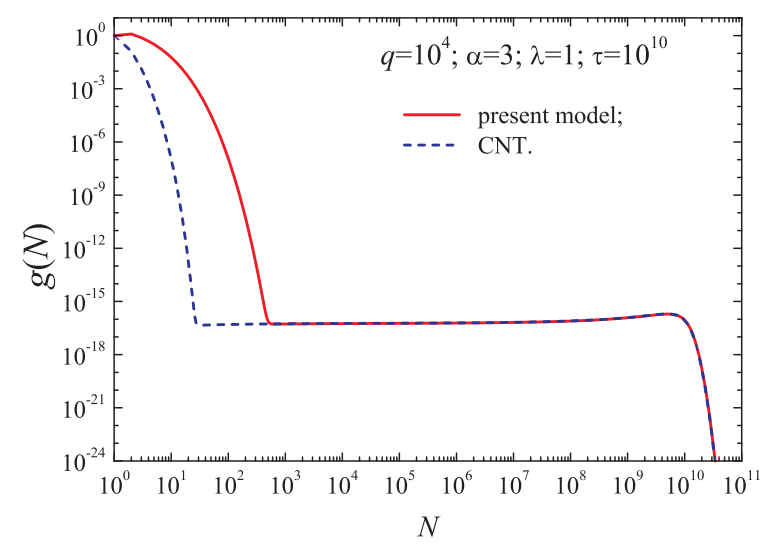

Figure 2. (Color online) A distribution of precipitates at a given time calculated within the framework of CNT and this model.

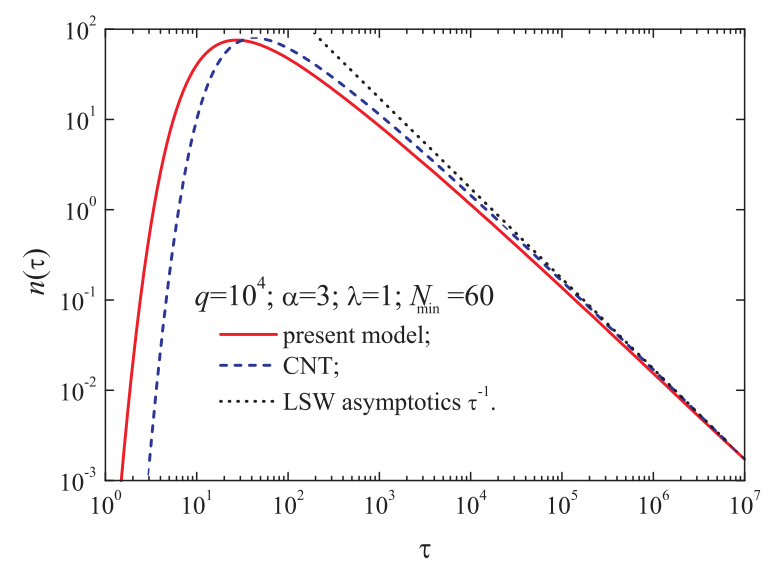

Figure 3. (Color online) The concentration of precipitates as a function of time 37) calculated within the framework of CNT and this model, together with the LSW asymptotic law $\tau^{-1}$.

the total solubility limit, depending on the values of the model parameters, may exceed the solubility of monomers by several orders of magnitude.

Herein below, we compare the results of the present model for precipitation kinetics with those of CNT, for the same values of solute concentration in the matrix $q=10^{4}$ and the model parameters $\alpha=3$ and $\lambda=1$. In each calculation, the homogeneous state of a solid solution (only monomers, no precipitates) 
is taken as an initial condition.

Figure 2 shows a solution of the system of equations (24), (28) at $\tau=10^{10}$, with the rates of emission and absorption, given by this model [equations [29), 30)] and CNT [equations (31), 32] ]. The low- $N$ steep part of the curves describes heterophase fluctuations, while the high- $N$ part describes the precipitates that evolve according to the LSW theory. One can see that this model gives a much wider range of heterophase fluctuations than $\mathrm{CNT}$ does. At the same time, in the high- $N$ range, both models yield identical results. This result is in a qualitative agreement with several recent observations of subnanometer-sized clusters formed during ageing in supersaturated Fe-Cu [8], [9] and Ni-Al [10] alloys.

Figure 3 shows the concentration of precipitates in the range $N_{\min } \leqslant N \leqslant N_{\max }$ :

$$
n(\tau)=\sum_{N=N_{\min }}^{N_{\max }} g(N, \tau),
$$

where $N_{\min }$ is a lower limit cutoff, practically set by the resolution limit of an observation instrument. One can see that within the present model, the nucleation stage of the precipitation process occurs earlier than within CNT, and at the coarsening stage, the asymptotic LSW power law $n(\tau) \propto \tau^{-1}$ is achieved within the present model later than within CNT.

In summary, the present model, based on the consideration of reversible elementary acts of migration of point defects across the precipitate-matrix interface in a solid solution, allows for a direct derivation of the rates of emission and absorption of solute atoms at the interface and, therefore, makes it possible to study the kinetics of homogeneous precipitation from solid solutions. Compared with the classical nucleation theory, this model predicts much stronger heterophase fluctuations and higher nucleation rates. The results obtained apply to the kinetics of phase transformations in any other system where the boundary condition of the type of equation (15) is applicable.

\section{Acknowledgements}

The author is grateful to Dr. A. Turkin for sharing his numerical code and to Dr. A. Abyzov for reading and commenting the manuscript.

\section{References}

1. Ostwald W., Z. Phys. Chem., 1897, 22, 289.

2. Lifshitz I.M., Slyozov V.V., J. Phys. Chem. Solids, 1961, 19, 35; doi 10.1016/0022-3697(61)90054-3

3. Wagner C., Z. Electrochem., 1961, 65, 581; doi 10.1002/bbpc.19610650704

4. Slezov V.V., Kinetics of First-Order Phase Transitions, WILEY-VCH Verlag GmbH \& Co. KGaA, Weinheim, 2009; doi $10.1002 / 9783527627769$

5. Schmelzer J.W.P., Slezov V.V., Abyzov A.S., In: Nucleation Theory and Applications, Schmelzer J.W.P. (Ed.), WILEYVCH Verlag GmbH \& Co. KGaA, Weinheim, 2005, 39-73; doi 10.1002/3527604790.ch3

6. Borisenko A., J. Nucl. Mater., 2011, 410, 69; doi 10.1016/j.jnucmat.2010.12.315

7. Becker R., Döring W., Ann. Phys., 1935, 416, 719; doi 10.1002/andp.19354160806

8. Zhang Z.W., Liu C.T., Wang X.-L., Littrell K.C., Miller M.K., An K., Chin B.A., Phys. Rev. B, 2011, 84, 174114; doi 10.1103/PhysRevB.84.174114

9. Dmitrieva O., Choi P., Ponge D., Raabe D., Tillack N., Hickel T., Neugebauer J., In: Scientific Report 2009/2010, Max-Planck-Institut fur Eisenforschung GmbH, Dusseldorf, 2010, 103.

10. Singh A.R.P., Mechanisms of Ordered Gamma Prime Precipitation in Nickel Base Superalloys, Ph.D. thesis, University of North Texas, 2011. 


\section{Нова кінетична модель осадження із твердих розчинів}

\section{О. Борисенко}

Національний науковий центр “Харківський фізико-технічний інститут”, вул. Академічна, 1, 61108, Харків, Україна

В цій моделі проведено розгляд оборотних елементарних актів міграції точкових дефектів (міжвузельних атомів та/або вакансій) через міжфазну границю виділення-матриця, що дає змогу отримати рівняння для швидкостей вивільнення та поглинання атомів домішки на границі. У порівнянні з класичною теорією нуклеації, ця модель передбачає значно сильніші гетерофазні флуктуації та більші швидкості нуклеації. Проте асимптотично, для великих розмірів виділень та довгого часу старіння, обидві моделі дають однакові результати, що збігаються з результатами теорії Ліфшиця-Сльозова-Вагнера.

Ключові слова: гомогенна нуклеація, кінетика фазових перетворень, осадження, точкові дефекти, міжфазна границя 